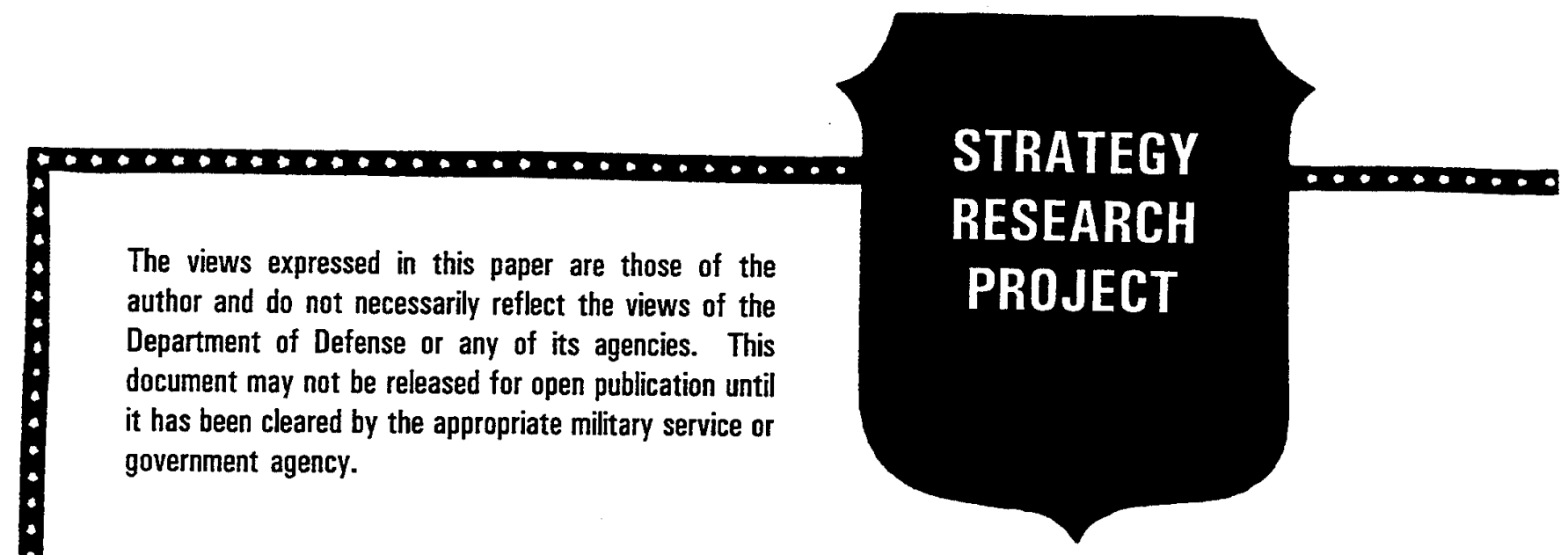

\title{
U.S. MILITARY ACADEMIC MEDICAL CENTERS: CROWN JEWELS OR WHITE ELEPHANTS?
}

BY

COLONEL EDWARD C. HUYCKE

United States Army

DISTRIBUTION STATEMENT A:

Approved for public release.

Distribution is unlimited

\section{5 usawc cassof of 198}

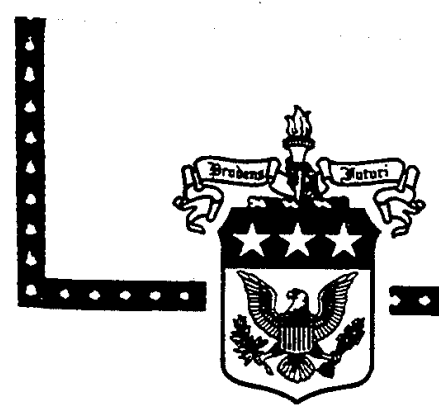

U.S. ARMY WAR COLLEGE, CARLISLE BARRACKS, PA 17013-5050 
The views expressed in this paper are those of the author and do not necessarily reflect the views of the Department of Defense or any of its agencies. This document may not be released for open publication until it has been cleared by the appropriate military service or government agency.

\title{
U.S. MILITARY ACADEMIC MEDICAL CENTERS: CROWN JEWELS OR WHITE ELEPHANTS?
}

\author{
by \\ Colonel Edward C. Huycke \\ United States Army \\ Colonel Giles F. Crider \\ Project Adviser
}

DISTRIBUTION STATEMENT A: Approved for public release. Distribution is unlimited.

\author{
U.S. Army War College \\ Carlisle Barracks, Pennsylvania 17013
}

UNCLASSIFIED 
ABSTRACT

AUTHOR: Edward C. Huycke (COL), USA

TITLE: U.S. Military Academic Medical Centers: Crown Jewels or White Elephants?

FORMAT: $\quad$ Strategy Research Project

DATE: $\quad 15$ April 1996 PAGES: 28 CLASSIFICATION: Unclassified

Managed care is the most important change in American

medicine since medicine organized along modern lines at the

beginning of the twentieth century. Civilian academic medical

centers, the crown jewels of twentieth century medicine, will

become so disadvantaged in the competitive marketplace under managed care that many are being forced to slash prices and reorganize services. The marginal ones will be forced to close. Military academic medical centers will also be affected by managed care. This paper examines the impact of managed care on military academic medical centers through evidence gained from interviews with senior executive military medical leadership. These leaders believe that military managed care will support military academic medical centers in their readiness missions. They conclude that managed care will enhance the position of military academic medical centers, rather than compete with them. 
The growth of managed care is threatening the survival of our academic medical centers. ${ }^{1}$

One observer of medical academia thereby assesses the impact of managed care on the largest, most prestigious institutions of twentieth century American medicine. Normally staid medical literature likewise echoes this ominous prediction:

The future viability of academic medical centers is threatened. ${ }^{2}$

Even a Washington Post editorial has added to the alarm:

The squeeze on academic medical education [and medical centers] comes more indirectly via the pressure to keep health care costs down; the urgency of that need to cut health care costs just makes the problem more intractable. ${ }^{3}$

These are dire words, indeed. But do they merely represent the hyperbole that sells magazines and newspapers? Or are they really describing some epochal change that is altering the way in which health care is provided and the way in which health care professionals are going to be educated and trained?

What are academic medical centers? What is managed care? How has managed care, the market force, impacted on academic medical centers, the institutions? Most importantly, are these dire predictions about civilian academic medical centers also applicable to military academic medical centers? Is the survival of military academic medical centers, which have been called the "crown jewels" of the military health care system, ${ }^{4}$ in jeopardy? Are these "crown jewels" to be rendered into "white elephants" in the coming era of managed care? 
This paper reviews the published accounts of the impact of managed care on civilian academic medical centers and then examines the effects of managed care on military academic medical centers. Interviews with senior Department of Defense medical and U.S. Army Medical Department executives have provided insights on the impact of managed care on military academic medical centers. We should begin this analysis with a shared understanding of the origins and missions both of civilian and military academic medical centers, along with a review of the tenets of managed care.

THE ACADEMIC MEDICAL CENTER

Academic medical centers are the centerpieces of 20 th century medicine. Formed early in this century, these, institutions brought medical education and training into the scientific age, offering a systematized, organized approach to medical research, and modern specialized treatment to patients with conditions beyond the capabilities of general practitioners. As Iglehart explains:

[Academic medical centers], which developed in response to changes in medical education in the early 20th century, have three missions that are critical to the maintenance of clinical excellence: graduate medical education, clinical and basic research, and the provision of a spectrum of patient care. ${ }^{5}$

Medical education includes the four years leading to the M.D. degree, while clinical training encompasses the following three to seven post-doctoral years that lead to specialization and certification. Education of nursing and allied health 
students (physical therapists and occupational therapists, for example) also is conducted at academic medical centers. Traditionally, nearly all educational and training activities have centered on the most expensive patient: the inpatient. Medical research at academic medical centers ranges from purely bench studies to large scale clinical trials involving many patients. Iglehart observes that:

In essence, [academic medical centers] are the primary conduits for transforming laboratory findings into therapies for patients. ${ }^{6}$

Finally, according to the Association of Medical Colleges, academic medical centers are:

. . first and foremost, providers of a broad range of health-care services.?

It is important to recognize that this "broad range of healthcare services" has meant a broad range of specialty services particularly dependent on high technology procedures. Primary care services, on the other hand, have not been represented extensively in academic medical centers.

In the U.S. Army, the Walter Reed Army Medical Center is the typical military academic medical center. It was permanently established in 1906. Its missions then, as now, are remarkably similar to the missions of civilian academic medical centers, aside from its unique, additional readiness mission:

A general hospital is needed in or near this city [Washington, D.C.] (a) For treatment of special cases. . . requiring treatment by a specialist. . . (b) For 
instruction in connection with the Army Medical School. . - (c) For expansion in time of war. ${ }^{8}$

Even now, in every regard, the Walter Reed Army Medical Center is comparable to a civilian academic medical center. Medical education at the undergraduate level is conducted there in conjunction with the Uniformed Services University of the Health Sciences, a M.D. granting institution, and with civilian medical schools such as Georgetown University. Training programs span the specialty spectrum (although family practice, a primary care specialty, is not represented among the training programs). Basic medical research is the mission of the walter Reed Institute of Research and the Armed Forces Institute of Pathology, both institutions located at the Walter Reed Army Medical Center. Likewise, clinical research is conducted at the Walter Reed Hospital. Of course, specialty care entirely comparable to the specialty care given in a civilian academic medical center is provided to active duty service members and their families, as well as to retirees and their eligible dependents.* Military medical readiness is a vital Walter Reed Army Medical Center mission that is not comparable to any mission of civilian academic medical centers. In the event of war or national emergency, Walter Reed Army Medical Center must be able to field a large team of medically competent, militarily trained health care professionals on short notice for worldwide

${ }^{*}$ Beneficiary is the all encompassing term used for a person eligible for care in the military health care system. 
deployment. The remaining personnel at the Walter Reed Army Medical Center must be capable of a rapid, orderly expansion in patient capacity to receive large numbers of medically evacuated causalities from a war zone.

So the Walter Reed Army Medical Center serves as an example of a military academic medical center. It is comparable in every way to its civilian academic counterparts, with the military readiness requirement as the only important additional mission. Just as civilian academic medical centers have held the central position in 20th century American medicine, so military academic medical centers have been considered the "crown jewels" of the military medical departments.

\section{MANAGED CARE}

Traditionally, the relationship among patients, physicians and payers--insurance companies, employers and the Federal government are the major ones--has been on a fee-for-service basis. Under this traditional fee-for-service system, physicians retained essentially complete autonomy in the determination and direction of patient care, while the payers remained in the background and paid the bill. Under this arrangement, however:

- . expenditures in the health care system are growing at a rate that is regarded as unsustainable by both private and public payers. Because the money that finances medical care flows through third parties, both patients and physicians have been less sensitive to rising health care costs than they would be if patients had to pay for care directly. ${ }^{9}$

But payers have become increasingly sensitive to these costs and 
have demanded redefining of the traditional relationship among patients, physicians, and payers:

America's private and public third-party payers . . . are persuaded that "managed care" plans will produce demonstrable savings as compared with the current cost trends of traditional fee-for-service medicine. ${ }^{10}$

Managed care is defined as

- . a system that integrates the financing and delivery of appropriate medical care by means of the following features: contracts with selected physicians and hospitals that furnish a comprehensive set of health care services to enrolled members, usually for a predetermined monthly premium; utilization and quality controls that contracting providers agree to accept; financial incentives for patients to use the providers and facilities associated with the plan; and the assumption of some financial risk by doctors ${ }^{11}$. . .

Under capitated managed care arrangements, therefore, providers or groups of providers contract with payers to provide all necessary care to a population for a fixed price. Providers who give unnecessary, inefficient, or more costly care are competitively disadvantaged, compared with more efficient providers. These less competitive providers risk elimination from the market unless they abandon their more costly practices. ACADEMIC MEDICAL CENTERS AND MANAGED CARE

Academic medical centers--with their training programs, with their research programs and with their intensive, technologically advanced patient care--are seen increasingly as too expensive by payers. Community medical centers, with only a patient care mission, have become attractive alternatives to the academic 
medical centers for health care payers like health maintenance organizations and government health care programs. Community medical centers can often provide specialty patient care services similar to that provided by the academic medical centers, but at a lower price. Community hospitals and physicians thus have a distinct competitive advantage over academic medical centers. Iglehart points out that:

As community physicians and hospitals, along with private payers, form binding ties around managed-care plans that enroll patients and lock them into their systems (or impose substantial financial penalties for seeking treatment outside them), the economic incentives of providers change to reflect the new imperative--containing costs. Physicians working under such arrangements are encouraged to use resources sparingly and to refer patients to doctors outside their network only if absolutely necessary. Some academic medical centers are beginning to experience the inevitable result of this pattern--fewer patient referrals. . . . The pressure on academic medical centers is further exacerbated by the proliferation of medical specialists who are practicing in the community, whether they are involved with managed-care plans or not, and the dwindling number of services that teaching hospitals are uniquely equipped to provide. These developments add up to the presence of excess capacity in many metropolitan areas, a lethal formula [for academic medical centers] in a system increasingly driven by price competition. ${ }^{12}$

The challenge to academic medical centers is stark: change or be eliminated.

Some academic medical centers have responded predictably by cutting prices. "Bundling" has emerged a favorite mechanism for reducing prices. As Iglehart notes:

Some [academic medical centers] . . have begun to bundle packages of services and offer them to third-party payers at a fixed price that combines both hospital and physicians' charges. ${ }^{13}$ 
In at least one instance, bundling has successfully reduced prices: The combination of hospital and physician's charges for uncomplicated coronary artery bypass surgery as a package saved $\$ 13$ million dollars over what would have been paid through the traditional Medicare arrangement. ${ }^{14}$ But officials of a New York City academic medical center say that in spite of such "an aggressive campaign to hold down costs, they are barely getting by. $" 15$

Many academic medical centers, however, have favored competing directly with health maintenance organizations for patients by starting, buying, or aligning with primary care networks of patients:

The academic medical centers in Philadelphia all seem intent on forming or becoming part of integrated health care systems as their prescription for survival. ${ }^{16}$

In theory, this primary care network would assure that the academic medical center's specialty services have a constant flow of patient referrals. Academic medical centers, however, have not yet completely succeeded in this transformation:

Few [integrated health care systems based on academic medical centers] have enrolled the number of members needed to make such a program work: The rule of thumb has been that a program needs about 200,000 members to furnish the number of patients necessary to train medical students and residents to provide at least routine care for heart attacks, pneumonia, and other common problems. ${ }^{17}$

One study estimates that as many as 1 million managed care enrollees are necessary to support such specialty services as 
organ transplantation or oncology at a major academic medical center. ${ }^{18}$ At the University of Pennsylvania, the managed-care target enrollment for its integrated system is 600,000 people, considerably short of the number needed to maintain highly specialized services. ${ }^{19}$ Cost-cutting and patient network building, alone or together, do not appear to offer academic medical centers a sufficient response to the managed care challenge--one that would assure their survival, with their current organizations intact.

Although not directly related to the competitive impact of managed care on academic medical centers, the reduction in Medicare payments and its support for graduate medical education (and also, therefore, academic medical centers) will make the face off between managed care organizations and academic medical centers that much more acute. Medicare currently provides about $\$ 4$ billion a year to academic medical centers to help cover the costs of training medical students and residents and to support the medical care of indigent patients. ${ }^{20}$ The Republican Congress, however, has made a priority of reducing the Medicare program by as much as $\$ 270$ billion over seven years. ${ }^{21}$ Despite proposals to federally support graduate medical education with as much as $\$ 16$ billion a year through a trust fund outside the Medicare system, Senator Christopher J. Dodd, a Connecticut Democrat, recently said:

I know and appreciate that the House and the senate plan contain provisions that to some extent recognize the importance of our [academic medical centers]. . . . [But] I 
would also ask you not to be deluded, not to fool ourselves, that there are serious, serious shortcomings, in my view, in these budget proposals. Should these plans cutting Medicare by $\$ 270$ billion over seven years survive, [academic medical centers] will lose financially more than they gain. ${ }^{22}$

Dr. Spencer Forman, president of Montefiore Medical Center, an academic medical center in New York City, summarizes the range of effects of the fiscal pinch felt by academic medical centers nationwide:

We are in assault mode, caught in the crossfire of demands for reductions from Albany, reductions from Washington and a market that demands discounts. . . We are already impoverished. We can't surrender on all fronts and survive. - . The risk in a marked reduction of teaching dollars is not that teaching will stop; it's that the institution will have to close. Maybe you are giving us enough to train residents, maybe you aren't. But if you take $\$ 30$ million or $\$ 40$ million out of these institutions, they are in trouble. ${ }^{23}$

Clearly, this revolt of the payers--managed care and governmental organizations--has academic medical centers reeling. Survival has become the goal, but their survival is not assured. Schroeder predicts:

Only a few academic medical centers--with a lot of capital or a particularly advantageous market niche--may be able to continue to operate as they have for the past few decades. Some centers may disappear. Particularly vulnerable centers include those in inner cities and in areas with many competing hospitals. Several already have begun cutting staff members and slots for residents, and some [academic medical centers] are considering merging operations with others in the same urban area. ${ }^{24}$

Academic medical centers thus have suddenly lost their the "crown jewels" status in twentieth century American medicine. They now 
fear becoming the "white elephants" of a twenty-first century jungle dominated by intense competition.

\section{MILITARY ACADEMIC MEDICAL CENTERS AND MANAGED CARE}

Few significant organizational trends in civilian medicine fail to affect military medicine. We have noted that the founding of civilian academic medical centers in the early twentieth century paralleled the establishment of military academic medical centers. Also, in the 1930's and 1940's, American medicine was systematizing the specialty training of physicians by formalizing the preceptorship arrangement for training specialists into residency training programs at academic medical centers. At about the same time, in the fall of 1946, Major General Norman T. Kirk, Surgeon General of the U.S. Army, approved the first permanent residency programs at military medical centers, mirroring the formalizing trend in graduate medical education which was taking place at civilian institutions. ${ }^{25}$

It is no surprise, therefore, that U.S. Army and military medicine began to implement managed care techniques at the same time that American civilian medicine did. In the late 1980's, then Major General Alcide M. LaNoue, Commanding General, Health Services Command, U.S. Army led the way with the Army Medical Department's "Gateway to Care" program, military medicine's first large scale excursion into managed care. By the early 1990's, Dr. Stephen C. Joseph, Assistant Secretary of Defense for Health Affairs, led the implementation of the mammoth, triservice 
managed care plan, TRICARE.

Dr. Joseph describes TRICARE as "a regionalized, triservice interoperable, capitated budgeted and primary care oriented managed care system."26 This health care system, which provides care for all beneficiaries, is divided into twelve geographical regions and will be run on a regional basis. In each region the commander of one of that region's military academic medical centers will usually run the TRICARE program there. The system will provide direct care through miliary medical centers, hospitals, and clinics; further, it will contract for care under the terms of a TRICARE support contract in cases where direct care is not available. Payment to the contractor is to be capitated, rather than on a fee-for-service basis. When these support contracts have been put in place in each region, the lead agent will exercise control over the contractor by means of the TRICARE support contract. Such control is a critically important feature of TRICARE since it permits the military academic medical center commander to maintain oversight over all missions and to use contract resources only when they clearly support accomplishment of those missions.

Military academic medical centers are just as interested as civilian ones in the two most important points of competition in a managed care environment: continued patient referral for specialty services and cost reduction. Just as civilian academic medical centers must compete for patients, military academic medical center also must compete for patients within the military 
health care system. Many patients in need of specialized care have the choice of going to a military academic medical center or to a local civilian community medical center (or even a local civilian academic medical center). Despite a seemingly natural and automatic referral path from the local military medical facility to the military academic medical center, supported by the availability of an extensive air evacuation system, many military patients have opted for local care. Major General Ronald N. Blanck, Commanding General, Walter Reed Army Medical Center describes his staff's response to such competition for patients:

I was told by my Chief of Neurosurgery that we had a problem. He told me that our index cases in neurosurgery-those complicated surgical cases, such as brain tumors and aneurysms, necessary for training neurosurgical residents-were going down. He told me that if the Residency Review Committee were to come and look at our program and the program at Navy, the only two neurosurgical residency programs in the military, we would not have enough of these index cases at these two programs for even one program. . - I knew what was going on. Surveys showed that these cases that were seen initially at our local military health facilities were going for care at local medical centers. . . - [the Chief of Neurosurgery] actively marketed his program. to the local military facilities and he has been extraordinarily successful in bringing back cases to walter Reed that heretofore had gone out. How did he do that? Essentially, by providing access and by being user friendly. ${ }^{27}$

Walter Reed Army Medical Center's loss of referred patient population is similar to the erosion of patient population experienced by residency programs at civilian academic medical centers. But the response in the military situation was successful because of improved specialty service relations with 
the referring facility--not because the military specialty service underpriced a competitor. If, as this example suggests, direct competition on a price basis is not the only factor determining military specialty patient referral patterns, what are the other important ones?

Readiness for war, in fact, is the imperative that drives the survival of military specialty services and military academic medical centers. There is no disagreement among Department of Defense and U.S. Army executive medical leaders that military academic medical centers are crucial to medical readiness. According to Dr. Joseph:

. . our peace time mission and our war time mission, to an economist, are really a joined product. It is a non-starter to talk about separating these [missions] and to take down the peace time side, use those resources to build up the war time side and you get better readiness. It's non-logic. You have to have some adequate level of robustness of the peace time health care system in order to have the readiness. ${ }^{28}$

Commenting on the contribution of military academic medical centers to wartime readiness, Lieutenant General Alcide M. LaNoue, The Surgeon General of the Army, stated:

In the Second World War, we didn't have graduate medical education [and military academic medical centers], we had people good at field sanitation and at riding horses. The reason we were able to bring quality in is that we mobilized the Massachusetts General Hospital [a civilian academic medical center in Boston] and other large training centers. Essentially, we imported graduate medical education. We can't do that in the current environment and so, we need to have our institutions embedded. . . . So it [the academic medical center and graduate medical education as related to war time readiness] is a core essential. ${ }^{29}$ 
General Blanck concurs:

The size and diversity of specialties of [military] medical centers make them.. . critical to deployments. As we go down [in military end strength] the message I'm spreading is everybody has to be trained and everybody has to be deployable. ${ }^{30}$

Clearly, the senior executive leadership of the military health care system cannot envision a ready, deployable, high quality military medical force without military academic medical centers.

Nonetheless, like the civilian health care system, the military health care system has been beset by increasing costs. The military health system has further been subject to the downsizing that the entire Department of Defense has undergone as a result of the end of the Cold War. The pressures on senior military medical leaders to reduce these military medical costs have been heavy enough to threaten the survival of all but the deployable aspects of the military health care system. As Dr. Joseph has said:

Given the downsizing pressures, given the financial pressures.. . were we to leave, for example, [National Naval Medical Center at] Bethesda doing its thing and Walter Reed doing its thing . . . with very high probability, we would not be able to show the financial efficiencies or the end strength efficiencies that will allow us to survive. . . - Our costs would continue to rise and we would be in the same position as the civilian sector: unable to control costs, unable to compete outside the medical center walls. . - These fiscal and programatic efficiencies [due to TRICARE] are the substrate that allows us to keep the system that allows us to do the readiness. ${ }^{31}$

Thus managed care, in the military health care system, is a powerful tool that assures a high quality, deployable medical 
force by supporting the continued survival of the military academic medical centers. ${ }^{32}$ In Dr. Joseph's words:

The future of the military academic medical centers is dependent on the successful execution of TRICARE, a system of care that is regionalized, cost effective, capitated budgeted and triservice interoperable and, conversely, the medical centers will be made stronger to the extent they can draw on the features of that system. ${ }^{33}$

So, unlike civilian academic medical centers, which are at the mercy of the managed care organization's relentless progress toward minimal costs, military academic medical centers are beneficiaries of the military managed care system, using and tailoring that system to strengthen its own training programs. Rather than being a serious threat to the survival of the military academic medical center, the military managed care organization is merely another tool available to the medical center commander to improve readiness.

For military academic medical centers, the matter of Medicare reimbursement is also important. Like civilian academic medical centers, military centers need Medicare reimbursement. As Dr. Joseph explains:

If we solve Medicare subvention ${ }^{* *}$ and if we maintain our fiscal and programatic viability through the managed care initiative, then we will keep the [military academic] medical centers in roughly the same configuration we have now but with a more triservice flavor. If we don't solve [Medicare] subvention or we can't make the managed care

"* Medicare subvention is the term used to indicate the Department of Defense requested legislative relief that would allow Medicare payments to the military health care system for beneficiaries who are Medicare eligible. 
efficiencies work, they [military academic medical centers] either won't be there or they'll be skeletons. If we don't do both, then its over. ${ }^{34}$

But, the Medicare concerns notwithstanding, military academic medical centers appear to be better positioned for the future in a managed care environment than are their civilian counterparts. Medical readiness remains paramount. So military academic medical centers, aided by a carefully crafted managed care support plan, are the most logical organizations to achieve that readiness. In the final analysis, Dr. Joseph remains optimistic about the prospects for military medicine and military academic medical centers:

If I offered you three stocks: one was in the M[ilitary] $\mathrm{H}$ [ealth] S[ervice] S[ystem], one was in the University of Kansas and one was in.. - Columbia HCA [a for profit health service company], which one is a better place for you to invest right now? I think you can make a strong argument that the best place to invest is the MHSS. The University of Kansas is in deep trouble. . . A lot of the for profits are going to go bankrupt. There's going to be a very big shake out [among the for profits.] I think if we do our stuff right--the directions that have been set over the past four or five years were really wise ones--if we do our stuff right, we have as stable a future as you can have in this crazy economy. And certainly better than the [civilian] academics or certainly the for-profits. . . If all those "ifs" work, we're in pretty good shape. ${ }^{35}$

\section{CONCLUSIONS}

Managed care is the most important change in the delivery of and the payment for health care services since the organization of modern medicine in the early twentieth century. The basis of this epochal change is competition among providers for the business of organized, knowledgeable payers who are not 
interested in subsidizing indigent care, medical education and training, or medical research. The research and medical education missions of modern civilian academic medical centers are costly; these missions put these institutions at considerable disadvantage in the managed-care marketplace, since community medical centers offer most of the specialty care that academic medical centers do, but do not have to support research and medical education and training commitments. Civilian academic medical centers are not going to survive in their present form and in their present numbers under conditions set by managed care. Financially weaker ones will close. Some will survive by expanding into primary care, reducing research efforts, and funding those remaining research projects through private and corporate means. Further they will require faculty and staff to assume more day-to-day patient care tasks and they will move medical education and training from a primarily inpatient experience to primarily an outpatient one. Finally, most civilian academic medical centers will have to continue slashing prices. Academic medical centers, as currently configured, will continue to exist under managed care, but there will be many fewer of them. Civilian academic medical centers are fast becoming the "white elephants" of the managed care era.

The military medical system has not been immune to the ebb and flow of civilian medical organizational trends. So, it is not surprising that senior executive military medical leaders have examined the managed-care paradigm very carefully. For the 
military medical system, managed care has been doubly important because the military medical services not only provide care directly but they also contract for care when that care is unavailable to beneficiaries in the direct care system. But the application of any civilian organizational change to the military has to adapt to the requirements of readiness. Managed care, too, must enhance military medical readiness before it assumes any place in the military health care system.

Military academic medical centers play a central role in medical readiness by training high quality medical professionals for service in our deployable units and by giving the highest quality care to large numbers of service members evacuated from a war zone. Military managed care will have to support military academic medical centers in those roles. Therefore, military managed care cannot interfere with readiness required medical education and training at these centers.

The form of managed care being implemented in the Department of Defense now, TRICARE, does not threaten military academic medical centers. Indeed, the academic medical center commanders will have the ability to enhance the training and readiness needs of the Services by tailoring the TRICARE support contract to meet those readiness needs.

Military academic medical centers, therefore, are not directly threatened in the fashion civilian medical centers are. The size and number of military academic medical centers will continue to be driven by the medical readiness needs of the 
Nation, not by the whims of the market. Managed care is an important tool that will permit the academic medical center commander and other senior military medical executives to efficiently manage medical resources and to achieve their readiness goals more easily and completely.

Academic medical centers remain the crown jewels of the military health system. Their essential contribution to readiness assures that position. The managed care strategies being set into place now will continue to enhance that position well into the twenty-first century. 


\section{ENDNOTES}

1. Steven A. Schroeder, "Facing the Grizzly: Can Academic Medicine Beat the Competition?," The Chronicle of Higher Education, 10 November 1995, A52.

2. Jerome P. Kassirer, "Academic Medical Centers Under Siege," The New England Journal of Medicine 331, no. 20 (1994): 1370-1.

3. Editorial staff, "Medical Infusions," The Washington Post, 16 January 1996, sec. A, p. 14.

4. Colonel Michael J. Brennan, "Military Medicine for the Twenty-First Century: "To Shape the Future'", USAWC Military Studies Program Paper, (Carlisle Barracks, Pennsylvania), 1992, p. 42. Strictly speaking, Colonel. Brennan refers to the Army Graduate Medical Education program as the "crown jewels" of the Army Medical Department. The close relationship between graduate medical education and the academic medical centers, however, reasonably allows broadening this quotation to the academic medical centers without violating the intent of the good colonel Brennan's original quotation.

5. John K. Iglehart, "Health Policy Report: The American Health Care System--Teaching Hospitals," The New England Journal of Medicine 329, no. 14 (1993): 1052.

6. Ibid.

7. As quoted in Ibid., p. 1053.

8. Annual Report of the Surgeon General, 1902, p. 136-7.

9. John K. Iglehart, "Health Policy Report: The American Health Care System--Introduction," The New England Journal of Medicine 326, no. 14 (1992): 963.

10. John K. Iglehart, "Health Policy Report: The American Health Care System--Managed Care," The New England Journal of Medicine 327, no. 10 (1992): 742.

11. Ibid.

12. Iglehart, "Health Policy Report: The American Care System-Teaching Hospitals," p. 1055.

13. Ibid.

14. The Medicare Participating Heart Bypass Demonstration Project. Interim report to the nation by participant hospitals. (Statement distributed at news conference.) Washington, D.C.: National Press Club, 13 July 1993 as quoted in Iglehart, "Health 
Policy Report: The American Care System--Teaching Hospitals," p. 1055 .

15. Elisabeth Rosenthal, "Leading Academic Hospital, Squeaking By, Seeks Merger," New York Times, 8 July 1995, sec. A, p. 1.

16. John K. Iglehart, "Health Policy Report: Academic Medical Centers Enter the Market--The Case of Philadelphia," The New England Journal of Medicine 333, no. 15 (1995): 1021.

17. Schroeder, p. A52.

18. John E. Billi et al., "Special Article: Potential Effects of Managed Care on Specialty Practice at a University Medical Center," The New England Journal of Medicine 333, no. 15 (1995): 979-83.

19. Iglehart, "Health Policy Report: Academic Medical Centers Enter the Market--The Case of Philadelphia," p. 1022.

20. Stephen Burd, "Medical-School Leaders Remain Concerned Over cuts in Medicare," The Chronicle of Higher Education, 10 November 1995, A51.

21. Ibid.

22. Ibid.

23. Elisabeth Rosenthal, "Elite Hospitals in New York City Facing a Crunch," New York Times, 13 February 1995, sec. A, p. 1.

24. Schroeder, p. A52.

25. Major General Norman T. Kirk, The Surgeon General of the Army, "Gerow Plan for the Education of Army Officers," memorandum for Director of Organization and Training, WDGS, Washington, D.C., 8 October 1946.

26. Assistant Secretary of Defense (Health Affairs) Stephen C. Joseph, interview by author, 22 February 1996, Washington, D.C.

27. Major General Ronald N. Blanck, Commanding General, Walter Reed Army Medical Center, interview by author, 23 January 1996, Washington, D.C.

28. Joseph interview.

29. Lieutenant General Alcide M. LaNoue, The Surgeon General of the Army, interview by author, 9 February 1996, Washington, D.C. 30. Blanck interview. 
31. Joseph interview.

32. Ibid.

33. Ibid. Emphasis added.

34. Ibid.

35. Ibid. 


\section{BIBLIOGRAPHY}

Billi, John E., Christopher G. Wise, Elizabeth A. Bills, and Rita L. Mitchell. "Special Article: Potential Effects of Managed Care on Specialty Practice at a University Medical Center." The New England Journal of Medicine 333, no. 15 (1995): 979-83.

Blanck, Major General Ronald N. Interview by author, 23 January 1996, Washington, D.C.

Brennan, Colonel Michael J. "Military Medicine for the TwentyFirst Century: 'To Shape the Future." USAWC Military Studies Program Paper (Carlisle Barracks, Pennsylvania: 1992).

Burd, Stephen. "Medical-School Leaders Remain Concerned Over Cuts in Medicare." The Chronicle of Higher Education, 10 November 1995 , p. A51.

Editorial. "Medical Infusions." The Washington Post, 16 January 1996, sec. A, p. 14 .

Iglehart, John K. "Health Policy Report: Academic Medical Centers Enter the Market--The Case of Philadelphia." The New England Journal of Medicine 333, no. 15 (1995): 1019-23.

- "Health Policy Report: The American Health Care System--Introduction." The New England Journal of Medicine 326, no. 14 (1992): 962-7.

- Health Policy Report: The American Health Care System--Managed Care." The New England Journal of Medicine 327 , no. 10 (1992): 742-7.

- "Health Policy Report: The American Health Care System--Teaching Hospitals." The New England Journal of Medicine 329, no. 14 (1993): 1052-6.

Joseph, Assistant Secretary of Defense (Health Affairs) Stephan C. Interview by author, 22 February 1996, Washington, D.C.

Kassirer, Jerome P. "Academic Medical Centers Under Siege." The New England Journal of Medicine 331, no. 20 (1994): 1371-1.

Kirk, Major General Norman T. "Gerow Plan for the Education of Army Officers." Memorandum for Director of Organization and Training, WDGS. Washington, D.C., 8 October 1946.

LaNoue, Lieutenant General Alcide M. Interview by author, 9 February 1996, Washington, D.C.

Report of the Surgeon General of the Army. (Washington, D.C.: 
1902) p. 136-7.

Rosenthal, Elisabeth. "Elite Hospitals in New York City Facing a Crunch." New York Times, 13 February 1995, sec. A, p. 1.

- "Leading Academic Hospital, Squeaking By, Seeks

Mérger." New York Times, 8 July 1995, sec. A, p. 1.

Schroeder, Steven A. "Facing the Grizzly: Can Academic Medicine Beat the Competition?" The Chronicle of Higher Education, 10

November $1995, \mathrm{p}$. A52. 